\section{Psychotherapeutic Effect of Using Songs and Music for the Promotion of Basic Education Among Adult Learners: An Analysis}

\section{Adeshina Abideen Olojede}

Department of Continuing Education and Community Development,

Faculty of Education and Arts,

Ibrahim Badamasi Babangida University,

Lapai, Niger State

Submitted: 06 January 2019

Accepted: 02 July 2020

Published: 30 November 2020

Corresponding author:

\section{A. A.Olojede}

DOI: 10.19044/esj.2020.v16n31p210

(c) Copyright 2020 A.A.Olojede Distributed under Creative Commons BY-NC-ND 4.0 OPEN ACCESS

\begin{abstract}
Various teaching methods and approaches have been researched and used in nonformal education, but the abstract technique of songs and music is uncommon. The peculiar characteristics of adult learners make teaching and learning to be complex. This study is experimental. Seventy-six (76) adult learners were purposefully selected and divided into two groups of thirty-eight (38) each. Group A was exposed to songs in both Nupe and English language over a period of time. Observation and narrative methods were used to study the effect of songs and music as a tool for the facilitating of learning among adults' learners. The facilitators encouraged the learners to identify new words which were written separately on boards to spell and pronounce. Learners in Group B were exposed to the normal learning process of using primers to facilitate learning. At the end of one month, both groups were examined and evaluated. Data were analyzed using percentage. The results of the experiment showed that the learners in Group A exhibited more than $80.0 \%$ of success in assimilation as against Group B with $38 \%$ success when both were examined. 31 out of the $38(81.5 \%)$ learners from Group A can identify and read fairly with little assistance while 14 learners from Group B (36.8\%) can read in relation to music played and identification of words identified and written on board by the facilitator. Group A members were more enthusiastic to learn as they were involved in generating means of learning; they were able to identify words and produce sentences from the words written on the board. The
\end{abstract}

How to cite this article

Olojede, A.., (2020). Psychotherapeutic Effect of Using Songs and Music for the Promotion of Basic Education Among Adult Learners: An Analysis. European Scientific Journal, ESJ, 16(31), 210. https://doi.org/10.19044/esj.2020.v16n31p210 
study also showed that songs and music produce a psychotherapeutic effect that soothes the learning process and produce a positive outcome while teaching adult learners. The paper recommends the inclusion of local songs and music into the non-formal education curriculum. Also, facilitators should be more creative in the teaching and learning process of adult education.

\author{
Subject: Education \\ Keywords: Adult Learners, Analysis, \\ Basic Education, Psychotherapeutic \\ Songs, Music
}

\section{Introduction}

Literacy has been found to be an indispensable foundation that enables young people and adults to engage in learning opportunities at all stages of the learning continuum. The right to literacy has also been argued to be an inherent part of the right to education. It is a prerequisite for the development of personal, social, economic, and political empowerment. Literacy is also an essential means of building people's capabilities to cope with the evolving challenges and complexities of life, culture, economy, and society (UNESCO, 2009). Education is also a necessity for the survival of man and is generally viewed as the most important instrument for change, progress, and development by all societies all over the world. Scholars believed and have argued that educating adults would go a long way to bring about the development we desire in the society. Hence, the importance of education and literacy development is emphasized (Omolewa, 1985; Aderinoye, 1997).

Literature has shown that no country can achieve sustained economic growth without attaining near universal basic education (UBE). Its goal is to universalize access to basic education, which includes pre-primary and primary schooling as well as basic life skills for youth and adults - as defined by OECD-DAC for the purposes of collecting data on aid flows (Hinzen, 2013).

In the Nigerian context, basic education includes primary, junior secondary, nomadic education as well as adult literacy. As a member of Group E-9 nations (UNESCO, 2017), Nigeria is committed to the total eradication of illiteracy. In spite of this, the nation's literacy rate is stagnantly rooted at 53 percent of the growing population that is estimated at about 170 million people (World Bank, 2012). Education statistics for 2012 and the upward review of the statistics show that only 14.1 million out of the 21 million children of school age are enrolled in primary schools. The completion rate was 64 percent while the rate of transition to junior secondary school was 43.5 percent. There is overwhelming evidence that these vital literacy indicators have not improved (UBEC, 1999, 2000 and 2005), and this has an implication on adult and non-formal education. 
Basic literacy (both formal and non-formal) in Nigeria has been hampered by many social, political, economic, and cultural factors such as insufficient number of schools and the quality of physical infrastructure like school buildings, school furniture and equipment, lack of books, writing materials and teaching supplies, as well as an insufficient number of qualified teachers, considerable number of dropouts and repetition of grades at the primary and middle levels.

Understandably, the impacts of adult literacy first appear in the individual learner by way of new cognitive behavior and ways of understanding reality which engender in the individual, a new self-concept accompanied by greater self-confidence and self-esteem. The ability to read will enable an individual to comprehend and use modern technology. Learner's ability to read and write will help to keep their privacy. Some new literates may be satisfied with just reading the scriptures (Bible and Quran), while others may want to read folk tales and the ancient epics of their culture. Some may want to read newspapers to find out what is going on in their immediate or wider surroundings. Utilitarian uses of literacy by individuals may include generating income for better livelihood or making one's voice heard in situations where social and political decisions are made.

Against the backdrop of several educational opportunities like formal and non-formal education available in Nigeria, unequal participation and access continue unabated among the citizens (Education for All (EFA); Global Monitoring Report, 2005; Federal Ministry of Education (FME, 2003); UNESCO, 2012). In response to the demand for equal opportunity to education for all, the Federal, State and Local governments have been making frantic efforts at providing access to educational distribution in the country. Such a move includes the establishment of parastatals like National Mass Education and Adult Education Commission (NMEC) and states agencies for adult education in 1990. Others include the Nomadic Education Commission and Universal Basic Education Commission among others. Universities and Colleges of Education have programs that cover adult and non-formal education. Non-Governmental Organizations and International Donor Agencies are not left behind. Nevertheless, illiteracy still exists.

Series of economic and psycho-social situations in Nigeria serve as stumbling block to learning for many. It has been recorded that adults have the feelings to learn. Hence, they enroll into adult education, but some always dropped out by the way. Examples of such economic problems include the inability to feed themselves, as well as house and cloth their family. There is massive unemployment among the youths while the adults' salary emolument is nothing to write home about. Thus, those uneducated adults find it difficult to survive. Such unstable minds are opened to induced stress, hence, requiring a redress in terms of help with mental and emotional health problems. It aims 
to enable patients, or clients, to understand their feelings and what makes them feel positive, anxious, or depressed.

The concern of adult educators and practitioners therefore now covers what went wrong and what can be done to right the wrong. To this end, various teaching methods and approaches have been researched in an attempt to find a solution for the sustainability of literacy among learners. While it is true that teaching and learning are complex, teaching adults is extraordinary because of the peculiar characteristics of adult learners. Various teaching methods have been used in adult education, but using the abstract technique of songs and music has not been researched and could be said to be uncommon in adult and non-formal education. There is a dearth of information on the use of songs and music as a technique of facilitating learning among adult learners in contemporary non-formal education. This paper intends to analyze the possibility of their inclusion in the promotion of basic education among adult learners.

\section{Statement of the Problem}

Nigeria has been involved in adult education development since the 1914 amalgamation. The South Western Region introduced free education which was extended to other regions in the late 60s. After independence, various agencies and parastatals were established to create access to education. Despite these efforts, about 53 percent of the current population is literate (World Bank, 2010). What went wrong? Is it the method of teaching or the curriculum? There is abundant literature on methods of teaching and characteristics and attitude of adults to learning, but there is a dearth of literature on the use of songs and music in adult learning. This paper, therefore, focuses on examining the use of song and music in the promotion of adult education as a way to establish permanent literacy and providing therapeutic effect among adult learners.

\section{Purpose of the Study}

The purpose of this paper was to report the possible effect of music and songs on the learning process. Primers have always been the means by which learning is facilitated in adult education. Other techniques have been adopted; however, the use of music and song is relatively new in adult education. To examine this, learners were exposed to different songs and music which were written on the board. The effect of listening to music and songs where new words were selected and written on the board for learners to copy and learn was recorded. Based on the reviewed literature, several research questions were formulated. 


\section{Research Questions}

The following research questions were raised to anchor the study:

1. To what extent will songs and music be relevant to basic literacy promotion among adult learners?

2. How have the beneficiaries been coping with the use of songs and music to attain permanent basic literacy skills?

3. What is the difference in the learning outcome between the learners in independent and dependent groups used for the study?

\section{Literature Review Adult Education}

Adult education is the practice of teaching and educating adults. It is imparted at the workplace or otherwise in classrooms or learning centers through extension or continuing education courses organized at the adult learning center, secondary schools or college and university levels more generally by adult education professionals. Adult education is also referred to as popular education and training for transformation or education for community mobilization or education for sustainable development. It has also been referred to as andragogy to distinguish it from pedagogy.

Pedagogy literally means the art and science of educating children and is often used as a synonym for all formal classroom-based teaching. More commonly, pedagogy signifies a teacher-centered education. Andragogy, in contrast, is defined as the art and science of helping adults learn. Its usage now is more broadened to include learner-centered education for people of all ages. Adult education differs from children's education in many ways. One very significant difference is that adults already have a fairly large amount of accumulated knowledge and experience with them. This knowledge and experience of adults coupled with their deep-seated attitudes can either add value to their learning experience or hinder it. Another significant difference between adult and children learning is that adults often seek practical applications and uses of knowledge, which they wish to learn effectively.

\section{Teaching Methods in Non-Formal Education}

Facilitating an adult learning process is a dynamic activity. Constant reflection, assessment, and change on the part of the adult education providers are necessary components in planning programs and determining the appropriate teaching methods. In this line, evaluating the learning process is most essential to have a fruitful learning outcome. Thus, it is imperative that various teaching methods are accessed for their practicability and otherwise. Just as what operates in pedagogy, teaching adult learners entails certain methods which, if properly propelled, help learners to attain permanent 
literacy. To achieve this, adult facilitators could use any of the following techniques in adult education:

- Demonstration

- Role-Playing

- Field Trip

- Hands-on practice

- Field Trip

- Clinic

- Simulation/Games

\section{Characteristics of Adult Learners}

Majority of adult learners share the following similarities:

1. They prefer a learning structure that emphasizes the flexibility of time and pacing, heterogeneity of group membership, individualization with self-pacing, self-selection of learning activities, and interaction with a facilitator.

2. They prefer to learn from each other, even from those with divergent views. They are seemingly unwilling to assume risks. They do better in a climate of trust where differences are accepted. They tend to be critical of instructors who insist that there is only one right way to think or perform. They come to class with very definite expectations, and they value an instructor who responds to those expectations. Adults value learning experiences that have a rather immediate pay-off.

3. Adults want to be participative learners. They do not want to sit through long lectures; they want to play an active role and have constructive feedback about their performance. They tend to be receptive to cooperative learning that has a problem-solving orientation (Glatthorn, 1990).

4. They prefer a learning structure that emphasizes the flexibility of time and pacing, heterogeneity of group membership, individualization with self-pacing, self-selection of learning activities, and interaction with a teacher.

5. They prefer to learn from each other, even from those with divergent views. They are seemingly unwilling to assume risks.

6. They do better in a climate of trust where differences are accepted.

7. They tend to be critical of instructors who insist that there is only one right way to think or perform.

8. They come to class with very definite expectations, and they value an instructor who responds to those expectations.

9. Adults value learning experiences that have a rather immediate payoff. 
These findings have clear implications for adult learning. It is quite likely that the educational programmes that reflect these preferred structures and practices will be much better received than those that ignore what is known about adults learning preferences. Such practices and structures can be the incentive that will enhance adult learners' motivation to pursue programmes.

\section{Songs and Music as a Form of Teaching Method}

Music has always been seen as a way of life. It is embedded in the culture of man. It is universally accepted to soothe men religiously and socially. It provides identity with which man is known. In religion, be it modern or core traditional, music performs ritual functions. It elicits affirmation of acceptance of the deities. Both Muslim and Christians use music and dance to worship and "probably appease the Gods". Traditionally, man uses music and dance to appease gods such as Ijala for Ogun (the god of Iron); Iyere Osun for Ifa worshippers, same goes for Sango (god of thunder); Yemoja (sea goddess) and so on.

Expanding the use of music, Salcedo (2010) affirmed Bancroft (1985) that the familiar adage, that music soothes the savage soul, comes from the interpretation of the Biblical verses in Psalms 33: 2, 3 (King James Version) in which music was used for mood-altering purposes. Music has been shown to have physiological benefits including lowered anxiety, heart rate, pain, and blood pressure, as well as improved respiratory rate, recovery, and tension relief. Listening to music has been shown to "cause changes in blood pressure, blood flow, posture, respiratory rate, pulse rate, and general activity" (Olojede, 2016).

Listening to music engages the whole brain, thus, stimulating cognitive performance in a range of non-purely musical activities such as language and memory tasks (Neurosci, 2013). Recent studies (Racette \& Peretz, 2007; Moussard, Bigand, Belleville \& Peretz, 2012) reported a perturbing effect of music on the memorization of verbal material. A consistent part of the literature (Thompson, Moulin, Hayre \& Jones, 2005; Racette, Bard \& Peretz, 2006; Simmons-Stern, Budson \& Ally, 2010) claims that music can have a positive effect on memory in both healthy and clinical populations. Thus, results showed an effect of music on subsequent item recognition memory performance, although this did not extend to a source memory performance (Neurosci, 2013). Music played during encoding facilitated item recognition.

In the modern world, a large proportion of popular music enjoyed around the world has its roots in American genres. From blues to hip-hop, to rock \& roll, to house and techno and to jazz, the DNA of American music can be felt all over the world. However, much of the folk and traditional music found in the United States has its roots in the traditions of other countries. 
Music like reggae has its root in Jamaica while Apala, Fuji and Sakara are from Nigeria. African and Nigerian music to be specific could be understood within the context of the cultures of the people that listen and enjoys it.

Listening to music has been established to have a soothing effect on the psychology of people that listen to it. In fact, according to Gardner (1985), music as a problem-solving tool suggests that all individuals without brain damage possess some degree of musical intelligence. It is on that note that he concludes that musical intelligence in the classroom combines the theory of multiple intelligences with actual classroom learning. Application of music in foreign language classes could allow teachers to use the students' musical intelligence and their musical interests to achieve mastery of language skills (Gardner, 1985).

Literature has established a correlation between music and learning. Overy (1998) reported a study where children were exposed to a curriculum emphasizing music instruction over language and mathematics. Results showed that students in the music instruction group improved in language and reading, yet they were not worse at mathematics than students who had spent more time on these subjects without the additional music instruction. Learning to listen for changes in pitch in music may promote the ability to sound out new words. Therefore, there seems to be a correlation between language and music reading abilities. Some very early studies (Cooley, 1961; Dalton, 1952; Hutton, 1953; Maze, 1967; Wheeler \& Wheeler, 1952) affirmed varying degrees of correlation, all positive, between language reading ability and music reading ability even when children presented learning difficulties. Additionally, Hurwitz, Wolff, Bortnick, and Kokas (1975) found that the development of reading skills in young children involved in a music programme tended to accelerate over a prolonged period of time.

Many studies from field of education systems, neurophysiology and other sciences show to us that music has big influence on human beings, especially on children and their cognitive and psychophysical development. About good influence of music, we also have evidences in neurological researches on music and rhythm stimulation, which provide to us unbelievable information about work of cerebral cortex during listening music and playing music instrument (Gojmerac, 2018). Music and songs were said to have a universal appeal and ubiquitous presence in most people's daily lives, hence have all the prerequisites to become an effective teaching resource in this respect (Bokiev, Bokiev, Aralas, Ismail, \& Othman, 2018).

Recalling unfamiliar words can be burdensome to most learners; however, music may ease the process. Wallace (1994) compared immediate and long-term recall of spoken texts to texts learned with music. Results of the study indicated that recall was significantly greater with music than for the spoken condition. On the other hand, when the music was too difficult or the 
melody remained unlearned, it impaired recall. The study suggests that simple musical song can transform ordinary text into information that is effectively retained and recalled when needed. In addition, melody provides sequential information, line and syllable length information, chunk linking, and rhythmical information that have the potential for making an accurate reconstruction of the text.

\section{Methodology}

This study was an experimental study inspired by McElhinney and Annett's study (1996) as used in Salcedo (2010). Seventy-six (76) learners were selected for the study from Lapai Literacy Clinic Foundation, an NGO established as a community service in I.B.B. University, Lapai. They were divided into two groups with each group having thirty-eight (38) learners that were purposefully selected. Group A was exposed to various songs and local music in both Nupe and English language over a period of six months, while Group B (Control Group) was not. The respondents comprised of newcomers into literacy programs (Basic Literacy Class, are those that have never been to school or experience learning activities before).

The class was picked because of the following reasons:

a. Many of the learners had never been to school before while some dropped out for one reason or the other and therefore have not acquired basic literacy;

b. As an experimental study, it is better to use the newcomers in order to ascertain the veracity of the instruments;

c. The respondents are readily available anytime they are needed for assessment and evaluation of the effect of the instruments and are really committed to learning.

The learners' enthusiasm because of the learning environment (IBB University), as well as the learning process, also facilitated how the respondents were selected.

The main instruments were Focus Group Discussion, which entails the observation of learners' performances after a period of six months of learning and interview. The researcher of this study served as the moderator and facilitated the group discussion with an observer/note taker. The moderator was guided by questions that were used to elicit information from the group, while the trained note taker recorded key issues raised and other factors that may influence the interpretation of information.

FGD Guides; The FGD sessions covered such issues as:

a. Provision for learning materials like primers, writing books, pencils, and so on by the organizer of the program. 
b. Main reason/need of the learners in enrolling for a literacy class.

c. Song(s) or music they love listening to both at home and at the literacy class.

d. Do they count music or songs as a waste of time in education?

e. The skills acquired and used by the learners (e.g., writing, reading and numeracy).

f. Has using both music and songs been beneficial to them and others? (Using the skills of 3R to improve their lives).

g. Would they recommend the use of music and songs for others?

h. Any regrets in registering for the literacy activity?

\section{Discussion of Findings}

Research Question 1: To what extent will songs and music be relevant to basic literacy promotion among adult learners?

Figure 1 shows a song composed and sang by a learner in Group A. The learners in the group whose ages ranged between thirty-five and fifty years had been exposed to English Alphabets, could identify and pronounce between five to seven letter words, and a majority of them (68\%) had been to school (basic II equivalent to primary three in the formal education sector) and have acquired a preliminary knowledge about education. However, they dropped out because of one reason or the other. They were encouraged to identify various songs or music in Nupe language which they sang while the facilitator wrote the same on the board.

Control group listened to the facilitator identifying and pronouncing various words in the songs as written on the board. They followed their facilitator doing the same. This method paved way to what Smith (1992) established that listening is a very large part of school learning, with students spending an estimated 50 to 75 percent of classroom time listening to the teacher, to other students, or to media. The story is not all that different in adult learning as learners are expected to listen (in this case to music or songs composed by their colleagues). To Mayesky (1986), learning to listen is a prerequisite to listening to learn; hence, encouraging adult learners to listen to music soothed their mind, rekindle their interest, and provides foundation for reading development and an assimilation of what was sung.

Based on their interpretation of the song in their native language, the facilitator translated the song into English language and at the same time exposed the learners to identify new words in both Nupe and English language. The new words were spelled and learners wrote same in their note books. Some of the songs used for the study are as shown below: 
Figure 1. Translating a Nupe song to English

\begin{tabular}{|l|l|}
\hline Nupe Song & English Version \\
\hline Man nya Makaranta 2x & Teacher 2x \\
Ganya adeawo 2x & Tell them and be heard 2x \\
Muhammadu Kobo yi ba bonna... & In this our Muhammadu Kobo Centre \\
Yiga de man dozhi nwa bea & There cannot be any teacher like you \\
Ganya adeawo & Tell them and be heard. \\
\hline
\end{tabular}

The outcome of the exercise shows the learners eagerness to learn more. They were able to catch up with the English equivalence for certain words identified in the songs:

Man $=$ Teacher,

Ganja $=$ Tell them

Makaranta $=$ School

Ganya adeawo $=$ Tell them and be heard

Figure 2. Translating a Nupe song to English

$\begin{array}{ll}\text { Yiji yebo soko (2x) } & \text { We thank God }(2 \mathrm{x}) \\ \text { Yan makaranta } & \text { For establishment of this school } \\ \text { Na kpe yayi dana } & \text { May allah peace and blessing } \\ \text { Soko yayi saa } & \text { Be upon us now } \\ \text { Be nasaree } & \text { And always } \\ \text { Amin. } & \text { Amen }\end{array}$

The learners happily sang the songs, joyfully danced while clapping, and they mastered the spelling of words like teacher, school, Muhammadu, Center, etc. Many of them were able to spell the words as written on the board by the facilitator.

Introducing the national anthem to learners as shown in Figure 3 was done to encourage national identity, patriotisms among learners, and to encourage oneness as Nigerians. The learners listened to the music and were taught the national anthem. After two weeks of exposure, the learners were allowed to carry out various activities to determine the level of acquisition. The outcome of the experience showed that learners were able to identify two, three, four, and five letter words from the national anthem. They were able to give new words of the same letters on their own.

Figure 3. National Anthem

Arise, O compatriots,

Nigeria's call obey

To serve our fatherland

With love and strength and faith

The labour of our heroes past

Shall never be in vain

To serve with heart and might

One nation bound in freedom, 
Peace and unity.

The respondents were able to carry out the following activities after the singing of the national anthem:

1. They identified three letter words used in the anthem (one, and, our).

2. They mentioned four letter words (call, obey, past, vain).

3. They spelt and pronounced any five and six letter words in the anthem.

4. They pronounced and wrote the following words:
(a) Love
(b) Obey
(c) Faith
(d) Nation
(e) Peace
(f) Unity
(g) Freedom
(h) Fatherland

5. How many letters are in the following words? They counted and wrote:
(a) Nation
(6)
(b) Freedom
(c) Peace
(d) Nigeria
(e) Fatherland (10)

Research Question 2: How have the beneficiaries been coping with the use of songs and music to attain permanent basic literacy skills?

Table 2. Different measurement timings and measures of the Analysis

\begin{tabular}{|l|l|l|}
\hline $\begin{array}{l}\text { Timing } \\
\text { Lxposure to } \\
\text { Learning) }\end{array}$ & Measures & $\begin{array}{l}\text { Exposure to song and music } \\
\text { on learning outcome }\end{array}$ \\
\hline Before & $\begin{array}{l}\text { Prior knowledge/skills } \\
\text { Learners' } \\
\text { satisfaction/attitude/perception } \\
\text { towards learning system/tool } \\
\text { Baseline information about } \\
\text { self-efficacy and the local } \\
\text { culture identity }\end{array}$ & $\begin{array}{l}\text { Elementary knowledge and } \\
\text { identification of alphabets } \\
\text { Fear and unstable mind } \\
\text { among learners }\end{array}$ \\
& $\begin{array}{l}\text { Inferiority complex as failure } \\
\text { and a never-do-well was } \\
\text { exhibited } \\
\text { behaviors/patterns } \\
\text { Participation in collaborative } \\
\text { activities }\end{array}$ & $\begin{array}{l}\text { Individual and group reading } \\
\text { encouraged } \\
\text { Emotional stability, fear } \\
\text { removed and social interaction } \\
\text { encouraged }\end{array}$ \\
\hline After & $\begin{array}{l}\text { Learning performance } \\
\text { Learners } \\
\text { satisfaction/attitude/perception } \\
\text { toward learning system/tool }\end{array}$ & $\begin{array}{l}\text { Learners were able to read } \\
\text { and write well. }\end{array}$ \\
\hline
\end{tabular}




\begin{tabular}{|l|l|l|}
\hline $\begin{array}{l}\text { Perception of learning skills } \\
\text { (problem-solving/inquiry } \\
\text { skills, collaborative skills) }\end{array}$ & $\begin{array}{l}\text { Self-confidence and ability to } \\
\text { use communicative skills was } \\
\text { experienced. } \\
\text { Fear of failure removed. } \\
\text { Interest in further studies } \\
\text { shown. }\end{array}$ \\
\hline
\end{tabular}

Source: Field Study, 2017

Table 2 above showed the pre and post effect of beneficiaries' efforts on literacy acquisition. It shows that learners' attitude to education that was low at entry into the program improved as they were exposed to collaborative and participatory approach in learning. Their capability to retain learning experiences improved as they were able to acquire skills with which they solved personal problems. In addition, their self-esteem and confidence were also developed. Some of the learners exhibited interest to further their education. Some that were initially shy gained confidence. Their social interactions improved through individual and group reading.

\section{Research Question 3: What is the difference in learning outcome among the learners in group $A$ and group $B$ ?}

At the end of the experiment, both groups were exposed to a test. The outcome of the experiment reflects regular attendance in both groups. The learners were more enthusiastic to learn. Seventy-six percent of the learners in group A were above average, while 52\% were in group B. Most of the experimental group could form words with fewer efforts, while the control group was given a guide before such exercise could be completed. Experiment group (Group A) exhibited much confidence and collaborative efforts in learning more than group B. The outcome of the learning experiences among the learners in group A and group B showed that Group A learners were able to identify two, three, four, and five letter words from the passage easily and they were able to give new words of the same letters on their own than Group B learners. Reading speed among Group A was faster than Group B. However, there were not many differences in writing skills between the two groups.

It was evident that learners in both groups have adequate knowledge of the reason they were involved in adult education programs; yet, the control group were optimistic about advancing the course of their participation in the program. Learners in Group A were also willing to encourage people to attend the literacy class, while Group B would wish to continue if they could remain in Group B. This signifies the interest and change of attitude toward the use of songs and music with their resultant effects on the learning process.

Reading ability and comprehension among Group A was better than in Group B. As earlier discussed, learners in Group A were able to read 
effectively and comprehend the message more than Group B. Thus, this finding is in line with Durkin (1993) and Harris and Hodges (1995) that intentional thinking is constructed through interactions between text and reader when appropriate methods of teaching are applied.

\section{Discussion of Findings}

The result of the experiment shows that the learners in Group A exhibited traits of complete learning experience than Group B as they were involved in generating means of learning. Furthermore, they were able to identify words and produced new sentences from the words written on the board. The study also showed and confirmed the study of Altbach, Berdahl and Gumport (2005) that dynamic curriculum can effectively produce improved learning outcome if properly managed as done in the use of songs and music to effectively change the attitude, orientation, and learning experiences of the learners. It is also evident that songs and music produce a psychotherapeutic effect in soothing the learning process and a produce positive outcome in teaching of adult learners. This agrees with Wallace (1994) study that a simple musical song can transform an ordinary text into information that is effectively retained and recalled when needed.

The classroom environment was friendlier in Group A than Group B because of the participatory nature experienced. The findings also showed that learning outcome improved as learners were able to read and write well. Their self-esteem improved, they gained self-confidence and the ability to use communicative skills. There is also the removal of fear of failure and establishment of interest in further studies shown. This finding agrees with a recent quasi-experimental study by Gromko (2005), which showed evidence that school children participating in music instruction exhibited improved phonemic awareness.

The outcome of the finding put to test the suitability of andragogy in teaching adults and pedagogy for youth and children as posted by Usman (2015) on the arguments that were based on the characteristic differences that exist between children, youth, and adults in their approaches to learning and readiness. Identification of words (two-letter words, three, four and more) is an indication of mastery and sustenance of literacy. The outcome of the experience in the study showed that the learners were able to identify two, three, four, and five letter words from the passage. They were able to give new words of the same letters on their own, thus, indicating permanent and sustained literacy.

As exhibited by some of the learners to further their education, the findings therefore extend the need and possibility of mainstreaming nonformal education into formal education and the gaining of lost confidence among the participants; the findings further corroborated with Olojede (2012), 
who advocated for the promotion of continuation of adult learners and provision of an avenue that makes such a platform possible. There were improvements among Group A on social interactions as individual and group readings were encouraged which fostered self-confidence, social interactions, and a high self-esteem among the group unlike what was obtainable in Group B. As Gromko (2005) concludes in his work, music instruction, while valuable for liberating the artistic and musical potential of every child, may significantly enhance children's language literacy as well. The same story could be said of adults learning as established in this study.

\section{Conclusion and Recommendations}

Literacy has been found to be an indispensable foundation that enables young people and adults to engage in learning opportunities at all stages of the learning continuum. The right to literacy has also been argued to be an inherent part of the right to education. Nigeria has been involved in adult education development as far back as 1914 amalgamation. However, little achievements have been shown for this. Literacy rate is still put at 53 percent of the estimated over 170 million citizens. Examination of the use of song and music in the promotion of adult education as a way to establish permanent literacy and providing therapeutic effect among adult learners became imperative.

The outcome of the experience showed that experimented learners were able to identify two, three, four, and five letter words from the passage easily against what was obtained in the second group since they were able to produce new words of the same letters on their own. The experiment shows that, if properly used, songs and music can be used as a teaching technique that is sustainable to the learning process. The outcome of the experiment showed that the experiment group wanted the continuity of the method because of the sustainability of literacy acquired; hence, they preferred to maintain the control group and furtherance of their class. Though the outcome of the exercise reflects a sign of rivalry between the learners in groups A and $\mathrm{B}$, yet it was established that both song and music served psychotherapeutic effects in the life of the participants. Clearly, there are dynamics between a facilitator and their learners. Understanding how the relationship affects the intended outcome can be a fundamental precursor to learning. This is because motivation may be one of the most important aspects of teaching adult learners. The results of this study revealed that facilitators innovation play a very important role in the success of learning. Recognizing and addressing those innovations would go a long way to improve the learning outcome of learners. Following the findings of this paper, teachers and facilitators and policy makers in literacy programmes should be encouraged to include possibility of incorporating local songs and music into the non-formal education curriculum. Also, facilitators should be more creative in the 
teaching and learning process of adult education. Facilitators should encourage participatory or group reading as an effective way of encouraging social interaction and confidence among adult learners. Music is a complex auditory stimulus which evolves through time and has a strong emotional impact; hence, facilitators should use those that relate with the context of the curriculum so as to arouse and maintain the interest of the learners.

\section{References:}

1. Altbach, P., Berdahl, R., \& Gumport, P. (2005). American higher education in the twenty-first century, (2nd ed.). Baltimore, MD: John Hopkins University Press.

2. Bancroft, W. J. (1985) Music therapy and education. Journal of the Society for Accelerative Learning and Teaching, Vol. 10, No. 1, pp. 319, 1985. (ERIC Document Reproduction No. ED 285 414).

3. Bokiev, D., Bokiev, U., Aralas, D., Ismail, L., \& Othman, M. (2018). Utilizing Music and Songs to Promote Student Engagement in ESL Classrooms. International Journal of Academic Research in Business and Social Sciences, 8(12), 314-332.

4. Cooley, J. C. (1961). A Study of the Relation Between Certain Mental and Personality Traits and Ratings of Musical Abilities. Journal of Research in Music Education, 9(2), 108-117. https://doi.org/10.2307/3344307

5. Durkin, D. (1993). Teaching them to read (6th ed.). Boston, MA: Allyn \& Bacon.

6. Federal Ministry Education FME (2003).

7. Ferreri, L., Aucouturier, J., Makii Muthalib, M., Bigand, E. \& Bugaisk, A. (2013). Music improves verbal memory encoding while decreasing prefrontal cortex activity: an fNIRS study.10.3389/fnhum.2013.00779. PMCID: PMC3857524

8. Glatthorn, A. (1990). Supervisory leadership: Introduction to instructional leadership. GlenView: Scott.

9. Gromko, J. (2005). The effect of music instruction on phonemic awareness in beginning readers. Journal of College Reading and Learning, 53(3), 199-209.

10. Gojmerac, I. (2018). Importance of Music in Education System. https://www.researchgate.net/publication/323167985

11. Harris, T. L. \& Hodges, R. E. (Eds.) (1995). The literacy dictionary: The vocabulary of reading and writing. Newark: DE: International Reading Association.

12. Moussard, A., Bigand, E., Belleville, S. \& Peretz, I. (2012). Music as an aid to learn new verbal information in Alzheimers disease. Music Percept. 29 521-531 10.1525/mp.2012.29.5.521 
13. National Bureau of Statistics (2010). Annual Report, Abuja.

14. Olojede, A.A. (2016). Knowledge, Adjustment \& Prevention of Infectious Diseases: Non-Formal Education as an Alternative Approach to Rural Community Health. Ibadan Journal of Educational Studies (IJES), Volume 16 No. 2.

15. Racette, A., Bard, C. \& Peretz, I. (2006). Making non-fluent aphasics speak: sing along! Brain 129 2571-2584 10.1093/brain/awl250.

16. Racette, A. \& Peretz, I. (2007). Learning lyrics: to sing or not to sing? Mem. Cognit. 35 242-253 10.3758/BF03193445

17. Salcedo, C. S. (2010). The Effects of Songs in the Foreign Language Classroom on Text Recall, Delayed Text Recall and Involuntary Mental Rehearsal. Journal of College Teaching \& Learning - June 2010 Volume 7, Number 6 (19).

18. Simmons-Stern, N. R., Budson, A. E. \& Ally, B. A. (2010). Music as a memory enhancer in patients with Alzheimers disease. Neuropsychologia 48 3164-3167

19. Thompson R. G., Moulin C. J. A., Hayre S., Jones R. W. (2005). Music enhances category fluency in healthy older adults and Alzheimers disease patients. Exp. Aging Res. 31 919910.1080/03610730590882819.

20. UNESCO (2017). E-9 Ministerial Meeting on Education 2030 Inclusive and Equitable Quality Education and Lifelong Learning by 2030: Challenges and Opportunities for E-9 countries. Dhaka, Bangladesh, from 5 to 7 February 2017

21. Usman, Y. H. (2015). Differences between Pedagogical and Andragogical Methods of Teaching and the Preference of Andragogy for the Teaching of Adults. International Journal of African and Asian Studies www.iiste.org. ISSN 2409-6938 An International Peerreviewed Journal Vol (6). 